\title{
Graham Huggan
}

\section{Affective Animals: Transspecies Encounters in Modern British Animal Writing}

Introduction. This essay presents a selective overview of modern, mostly post-Second World War, British animal writing. I will argue that this writing is driven by deepseated fears and anxieties that make a mockery of the clichéd notions with which it continues to be associated: the reciprocal warmth of animal companionship; the reinvigorating effects of experiencing the wild. While most of the essay is taken up with detailed readings of the primary texts, a few preliminary reflections on animal writing are needed. Animal writing is easiest to define by what it is not, that is, a sub-branch or ancillary form of nature writing. To be sure, nature writing - which is itself far from easy to define - frequently features animals, but these are not necessarily central to the texts' main interests, while those animals that do appear in them often tend to be part of larger scenarios that are either governed by readily identifiable aesthetic conventions pastoral, for instance - or are otherwise made to conform to an equally predictable template of human needs, motivations, and concerns. In animal writing, by contrast, animals are generally positioned front and center of the text and their subjectivities are explored in direct association with those of humans. Notwithstanding, recent claims to the effect that animal writing challenges species boundaries and/or the category of the human itself can sometimes be as forced as they are fashionable, while in its most triedand-tested forms, notably the beast fable, animals are still routinely used to shed light on human behavioral traits (mostly shortcomings and failings) that often have little if anything to do with animals themselves. (For a suitably wide range of views on modern and contemporary animal writing, see, for example, Armstrong; T. Baker; Herman; McHugh. For a broader palette still, see also the recently published Palgrave Handbook of Animals and Literature, co-edited by McHugh together with John Miller and Robert McKay.)

British animal writing is no exception to this general rule, though it certainly has its own idiosyncratic tendencies. These include the proclivity to describe largely failed attempts to domesticate wild animals, with sometimes devastating results for the human as well as the animal actors concerned. A pointer for this is the relative scarcity of wild animals in contemporary Great Britain, a self-proclaimed nation of animal lovers that also happens to be one of the most systematically denatured countries in the world. Wildness may be the de facto currency of nature writing in the US, but there is 
precious little scope for this in the UK, where wildness is hard to imagine and harder still to experience, and where particular (iconic) animals are more given to feature than particular (representative) landscapes as emblems for a "wild nature" that can only be captured with considerable effort and, even then, seems more likely than not to prove impossible to preserve (Huggan).

This might also help explain my choice of animal subjects in the material that follows. In the first section of the essay, I will focus on representations of hawks in works or parts of works by four reasonably well-known British writers, dividing these for ease of discussion into two consecutive sets of matching pairs. In the first of these, I will bring together J. A. Baker's The Peregrine (1968), which is widely considered to be a classic of modern British animal writing, with Kathleen Jamie's scattered observations on hawks in her 2005 collection Findings; I will then go on to make a further comparison between Helen Macdonald's award-winning 2014 memoir $H$ is for Hawk and the self-lacerating experiment after which it partly styles itself, T. H. White's weird-and-wonderful The Goshawk (1951).

My choice of hawks relates to the fact that they are simultaneously dangerous and endangered. Several species of hawk are currently listed in the UK as being either vulnerable or endangered, while hawks have historically been associated in the popular national imaginary with the heightened vision that brings with it an almost preternatural awareness of mental confusion or physical loss (Macdonald; see also Farrier). But if hawks are embodied warnings, these have not generally gone well heeded; and even if hawks themselves are protected, in making the decision to engage with them we are most certainly not. The wildest of wild birds, hawks are ruthless killers with the popular reputation of being untameable: to attempt to train a hawk is at best a perilous and at worst a life-endangering exercise, as Macdonald and, before her, White find out. Hawks are vulnerable creatures, to be sure, but it is human vulnerabilities that they bring into sharp focus; and the price for attempting to feed off their wildness may be sanity, possibly even life itself. In Baker's text, in particular, hawks have multiple associations with death - including the apparent wish for it. Through its unflinching visions of the predator-prey relationship, The Peregrine brilliantly succeeds in reversing the idea of human dominance over the animal, revealing instead a curious pathology of self-sacrifice connected to ongoing histories of human violence, including the contemporaneous threat of nuclear annihilation and (redoubled by proximity in The Goshawk) traumatic memories of world war. 
In the essay's second section, I turn my attention to a suite of texts that examine the relationship between humans and otters, ranging from two earlier beloved works, Williamson's Tarka the Otter (1927) and Maxwell's Ring of Bright Water (1960), to more recent footsteps journeys - Miriam Darlington's Otter Country (2012) - and experimental enactments: Charles Foster's Being a Beast (2016). As I aim to demonstrate, otters offer further shared opportunities in these otherwise stylistically divergent texts to reflect on the deep-seated nature and epic scale of human/animal violence. This encompasses the brutal violence done by otters, the still more savage violence done to otters, and those seemingly limitless forms of violence that are routinely perpetrated by human beings against each other - and themselves. In addition, otters, as these authors suggest in their different ways, are as fundamentally unknowable to us as we are to ourselves, nor are they anything like the biddable creatures that decades of sentimental literature and film have made them out to be (for a valuable corrective to this, see Allen). Being a Beast, in particular, cuts a riotous swathe through these flimsy veils of sentiment, but meaningful incisions are also made elsewhere, even in the muchmisinterpreted Ring of Bright Water. Finally, the fact that otters are co-listed with some species of hawk as vulnerable in the UK adds a further layer of piquancy to the texts, which may be traced to a triple crisis: a crisis of the environment, a crisis of representation and, within the overall context of (Western) modernity, a crisis of the modern dissociated self.

All three crises, my argument runs, are mediated through the human-animal relationship, which is framed whether explicitly or implicitly in affective terms. This relationship, inflected as it is through contemporaneous social anxieties, is nothing if not a troubled one. Context may go some way towards accounting for this, but only some way, the larger point I want to make here being that animal writing is rarely reassuring about the relationships we (humans) enjoy with animals, and more often distinctly unsettling in the insights it provides into our relationships, both with each other and with ourselves. Certainly, the texts I want to look at here are all disquieting to a greater or lesser extent, and several of them are shot through with violence. It is of course true that I have chosen to focus on texts that, in bringing out the nature of human/animal (human as animal) violence, are also the products of deeply troubled human personalities. It has been suggested, for example, that the human viciousness of Tarka the Otter, as well as the hideousness of Williamson's real-life politics, can be partly explained by his traumatic wartime experiences in the trenches, whilst The Peregrine, which is ostensibly the product of an unremarkable man's obsession with a remarkable creature, asks decidedly uncomfortable questions about the limits of human understanding and intelligence that cannot help but reflect back on the mysterious

Humanimalia: a journal of human/animal interface studies

Volume 12, Number 1 (Fall 2020) 
figure of the author himself. But animal writing, I want to insist, is a genre that seems generally well suited to bringing out the worst in humans. And it is also a genre that is less likely to reveal our capacity to reach out to nonhuman others than to comment on the modern dissociated sensibility: our otherness to ourselves.

A second, less contentious strand to my argument is that animal writing is necessarily if by no means exclusively about humans, and that it consequently offers a fascinating record of the human-animal relationship over time. More recently, this changing relationship has been a focal point for the burgeoning research field (also represented by this journal) of human-animal studies, which has sought to shed new light on the meaning of the human and the tangled interactions between human and animal worlds. Much work in this field now focuses on the symbiotic relationship between two early twenty-first-century philosophical developments, which - in a questionable kind of intellectual shorthand - are currently referred to as the "animal" and "affective" turns. The animal turn is based on the premise that animals, rather than functioning as projection screens for a variety of human concerns and interests, are self-constituting subjects in their own right and active material agents in their own terms (Kalof and Montgomery; Weil). The affective turn, meanwhile, focuses on the various processes by which human and animal bodies (or, perhaps better, human and other animal bodies) engage meaningfully with one another in situated ways that are irreducible to set behavioral patterns, and that involve open forms of mutual "becoming" or interactive "worlding" that belie the ontological stability implied by conventional understandings of the grounded self (Halley and Clough).

These two turns come together in what I will be referring to in this essay as the multifunctional figure of the affective animal. Affective animals are characterized not just by their broad emotional appeal but also by their situated capacity to affect human behavior. They may also be so named insofar as they are able to elicit public sympathy, and in this respect the figure of the affective animal becomes a kind of emotional cipher, a catalyst for media-generated activist and/or advocacy work (Nyman and Schuurman ). Not all animals function in this way of course, and one of the benefits of animal writing is that it does not restrict itself to so-called charismatic animals that are manipulated in such a way as to tug at our heart-strings or activate the recognition of "our" complicity in "their" plight. Indeed, one of the products of what might loosely be called an ecological turn (another turn!) in British animal writing has been the renewed attention to less obviously significant species within the larger framework of ecosystems in which - as has been known for several centuries - it is the insects and 
worms of this world that do the vital work. That these systems are subject to potentially catastrophic breakdown, and are far less stable than they seem, has also been known for quite some time, though today's "Anthropocene condition" (Purdy) has reinforced this. ${ }^{1}$ Hence the elegiac edge in modern British animal writing, an edge significantly sharpened by the unfolding consequences of the Anthropocene, which registers both the anticipatory fear of likely disappearance and the felt disappointment of actual loss. And hence another form of regret experienced in texts that reveal, through several layers of mediation, that direct access to animal worlds is increasingly limited, and that - for many species - these worlds may not be accessible at all.

But if the history of British animal writing is fraught in these and other ways, it also fights against its own melancholic impulses. Iconic British animals - badgers and barnowls, ospreys and otters - continue to feature in contemporary texts, often in numbers that belie their actual ecological status; and indeed, in some of these texts, long inventories of local species are delivered that play to the best traditions of the Darwinian sublime. Even the more hopeful texts, though, tend to be haunted by the fear of loss, and it is no exaggeration to say that contemporary British animal writing, combining the long Western traditions of the pastoral elegy and the beast fable, provides a set of more or less anthropomorphic stylistic exercises in human alienation from the natural world. I say more or less insofar as animal writing has historically gestured towards that which it can never achieve, that is, the human attempt to "become" an animal. Admittedly, some forms of writing have little or no intention of doing this, turning animals into little more than human beings, often vulnerable or putupon human beings, in numerous entertaining varieties of mock-disguise. But other forms, taking their cue from the latest ethological discoveries, offer a more scientific approach to the understanding of animal behavior, attempting an impossible-butnecessary reciprocity of vision in which human beings are both fashioning observers and sometimes unwilling recipients of a keenly experienced animal gaze.

While animal writing is by definition multisensory, it is the sense of sight that predominates in most cases, backed by a multifaceted history of empirical observation that has accompanied its most readily recognizable British variant, the first-person natural-historical account. This suggests that the study of animal writing might benefit from the various theories of the gaze that have been developed by contemporary visual theorists. One important point to bear in mind is that the gaze is not the same thing as the look. For Kaja Silverman, the look describes a visual category, often driven by personal desire, whereas the gaze describes a broader visual regime that is shaped by dominant social and cultural forces and frequently operates as an instrument of control

Humanimalia: a journal of human/animal interface studies

Volume 12, Number 1 (Fall 2020) 
and mastery that positions the subject in relation to what it sees $(134,156)$. For humans to look at animals, in Silverman's terms, always implies a certain degree of intellectual and emotional projection; within the broader framework of the gaze, it also opens up the possibility of a returned look that confirms the other as a subject in its own right (95). Within this general context, Wendy Woodward distinguishes between two kinds of animal gaze: an objectifying gaze that confirms (imagined) human superiority over animals; and a reciprocal gaze that acknowledges our "subjective kinship" with them (3). Woodward is committed to the possibility of placing humans and animals in what she calls a "continuum of kinship" (14); other theorists, notably Donna Haraway, suggest that humans and animals co-exist in a much messier entanglement of desires and forces that is by definition unbalanced and asymmetrical, and in which the possibility always exists that human interest in the animal is not reciprocated at all (24).

What does all this mean in the context of modern British animal writing? One thing it means is that animal writing, even given the scientific advantages of the times, remains as much an index of ignorance as a vehicle of insight into the phenomenal life-worlds of animals; as Jed Purdy starkly puts it, "we [just] don't know what an animal's life means, to it or to us" (244). Another thing it means is that this continuing ignorance can be brought to bear on the history of what we have done to animals; and in this second sense, contemporary animal writing operates within another kind of historical penumbra - that surrounding human remorse. This isn't to turn all animal narratives into moral tales, for as might be expected contemporary texts tend to be critical of their own moralizing tendencies, but it is to suggest that animal writing draws upon a conspicuously uncanny aesthetics that is driven by simultaneous unease and uncertainty over what it purports to represent.

Finally, a third thing it means is that the various uncertainties and failures embedded within the history of modern British animal writing are exacerbated by the current conditions of the Anthropocene, which matches the actual disappearance of animals in alarming numbers - to their metaphorical disappearance from our everyday lives (Berger; Lippitt). In contemporary writing these two forms of disappearance can easily start to blend in to one another, creating a grey area between extinction narratives, which document irrecoverable losses, and pseudo-extinction narratives, which build up apocalyptic atmospheres of disappearance even if the science tells us that this isn't necessarily the case. ${ }^{2}$ Recent work on extinction suggests that it is as much an imaginative failure as anything else (Heise; Van Dooren); contemporary animal writing 
fights all the more vigorously against this failure because it is one that it is fearful of repeating itself.

In what follows, I want to chart these various interconnected struggles, which are at once physical and psychological, representational and epistemological, via a sample of older and more recent animal texts. Backing up my earlier reflections on the animal gaze, I will turn first to two pairings of texts that illustrate the potentially visionary quality of modern animal writing while also showing its limits of vision in relation to the various "transspecies encounters" (Haraway) it wishes to enact. ${ }^{3}$

Hawk "I"s. All of Russia, it is rumored to have been said, emerged from Gogol's Overcoat. It is worth wondering whether something similar might be said of contemporary British animal writing and Baker's Peregrine, though it is really only recently, with the various high-profile accounts that have accompanied the golden jubilee of its publication, that Baker's hallucinatory, sometimes harrowing rendition of his experiences with the titular animal has come to get the acknowledgement it deserves. Like Gogol's quirky masterpiece, The Peregrine is both terrifying and distinctly odd, with both narrative accounts almost willing the real/imagined calamities they visit upon themselves. Famously, The Peregrine took ten years to write though the text itself is quite short and only covers six months or so of its author's obsessive tracking of peregrines in his low-key Essex neighbourhood. Robert Macfarlane, one of several contemporary nature writers to live in these birds' shadow, has described the text as being written in "ecstatic, violent, enraptored prose" (2). It is certainly true that the adjective "hawk-like" is as apt depiction of the text's style as it is of its subject, especially in relation to its hyper-concentrated focus on the world-creating, but also potentially world-destroying, properties of the human/animal eye. In fact, The Peregrine is a Symbolist work in the Blakean mould, albeit adapted to the late modern (mid twentieth-century) context of a nation still struggling with the collective traumas of two devastating world wars and the hawkish specter of another, in the shape of a potentially earth-destroying nuclear war.

In this context, to see is alternatively to select one's prey and to serve oneself up as the predator's willing sacrifice. The Peregrine moves alarmingly between these two opposing subject positions, never quite becoming the hawk (because its author cannot) but never quite succumbing to it either. At times, Baker seems to claim an almost shamanic affinity with the hawk, as in one close encounter when the hawk's eyes alight on the man's face, and Baker, part unnerved part mesmerized, consoles himself with the thought that "he regards me now as part hawk part man, worth flying over to look at

Humanimalia: a journal of human/animal interface studies

Volume 12, Number 1 (Fall 2020) 
from time to time but never wholly to be trusted; a crippled hawk perhaps, unable to fly or kill cleanly, uncertain and sour of temper" (146). More often, though, Baker admits that he knows little about either the hawk or its intentions. And for all the forensic precision of his observations, he cannot help but elevate the hawk into a kind of deathly symbol. This is all the more shattering in that peregrine falcons at the time were themselves a deeply endangered species: Baker's hawks are relentlessly pursued precisely because he fears that they may be England's last.

It would be an understatement to say that The Peregrine is fascinated by death; rather it embraces it. Almost lovingly detailed descriptions of fresh kills are intensified in the text by howling imprecations against man the killer:

No pain, no death, is more terrible to a wild creature than its fear of man. A red-throated diver, sodden and obscene with oil, able to move only its head, will push itself out from the sea-wall with its bill if you reach down to it as it floats like a $\log$ in the tide. A poisoned crow, gaping and helplessly floundering in the grass, bright yellow foam bubbling from its throat, will dash itself up again and again on to the descending wall of air, if you try to catch it. A rabbit, inflated and foul with myxomatosis, just a twitching pulse beating in a bladder of bones and fur, will feel the vibration of your footstep and will look for you with bulging, sightless eyes. Then it will drag itself away into the bush, trembling with fear. We are the killers. We stink of death. We carry it with us. It sticks to us like frost. We cannot tear it away. (113)

Scenes like this are almost too awful to behold, but they fix their raptor gaze on us. We want to look away and cannot; but if we are being honest with ourselves, we want to look as well. By looking, we are trapped into complicity, but like the hawk itself Baker seems indifferent to this. As Macfarlane rightly says, the text "suggests no basis for the establishment of an environmental ethics born of commonality," though he goes on to cite several instances of contemporary avian conservation initiatives that have been directly influenced by Baker's work (2-3). The main reason for Baker's indifference is that he remains firmly locked into a post-Romantic vision of his own solitude. Though we learn next to nothing about him in the text, he is ever-present in it - a helpless witness to his own sensory impoverishment, no doubt, but a witness nonetheless. The struggle for vision in the text (a literal one too: he was myopic) is Baker's own; he is not especially interested in whether or not we want to participate in it. It is also a struggle 
that is lost because it was too late in the first place. Whether it is too late or not for humankind to save itself is a question that the text leaves open for us; but it gives us little reason not to believe that Baker thinks it is too late to save himself.

For the Scottish writer Kathleen Jamie The Peregrine is, somewhat cautiously, a respected "classic of English natural history: a keen, affecting book about a man's affiliation and these particular birds" (35). But later in a chapter on peregrines and other birds of prey in her 2005 work Findings, Jamie is keen to know more: "Who was this man who could spend ten years following peregrines? Perhaps he was landed gentry. What allowed him to crawl the fields and ditches all day, all winter, until he could tell just by a tension in the air that there was a peregrine in the sky?" (43). As is characteristic for Jamie's work, these questions and speculations go unanswered, though she admiringly suggests that, for a man who would seemingly "annihilate himself and renounce his fellows," it must have been an "act of consummate communication to his human kind [to] step back into language and write a book still spoken of forty [now fifty] years on" (43).

I am not so sure that Baker's book is as generous to its audience as Jamie implies, but she neatly captures its overwrought qualities, the obsessiveness of both the pursuit itself and the language that attends to it, which slavishly imitates the hawkish properties of vitality and hunger that it knows it cannot appropriate for itself. Jamie's own approach to writing is very different: understated, unassuming, and always wryly conscious of the gap between the ambivalent freedom accorded to wild animals and the pleasurable constrictions of her domestic life. Above all, Jamie's writing performs the sly trick of managing to say a lot while repeatedly confessing to its own state of ignorance: self-interrogating phrases like "I have no idea," "I couldn't say," and "I'm beginning to wonder" are scattered through the pages of Findings, as they are in her other nature-oriented texts.

Temperamentally, Jamie's work combines the modern dissociation of the self with an updated form of Romantic negative capability. Acting together, these two qualities make for a style of writing that can appear clinically austere but is always charmingly honest, and that refuses to tie itself down to simple explanations: "I want to learn to notice, not to analyse," she says at one point in Findings, "to still the part of the brain that's yammering, 'My God, what's that? A stork, a crane, an ibis? Don't be silly, it's just a weird heron'" (42). For all Jamie's protestations to the contrary, this is modern animal writing to a fault, as aware of itself as of its subject and, acting as if to follow its own curiosities without feeling the need to rationalize or catalogue them, more likely to find

Humanimalia: a journal of human/animal interface studies

Volume 12, Number 1 (Fall 2020) 
things by default than by design - hence the fragmented structure and simulated randomness, both classic modernist strategies, embedded within her work.

There is an uncanny note to this work as well, as when Jamie - following in Baker's footsteps - describes the peregrines she has recently taken to watching in her Scottish Lowlands neighbourhood as "flicker[ing] at the edge of one's senses, at the edge of the sky, at the edge of existence itself" (47). Her vision, unlike Baker's, may not be impaired, but like his, her epistemological horizons are strictly limited: there is only so much that can be known about peregrines, and however attentive we are to their movements they will always have the capacity to move beyond our field of vision, ascending from approachable objects of scientific inquiry to sublimated subjects of folklore and myth.

Jamie's response to this, however, is to keep her own feet firmly on the ground, and to acknowledge that her world and that of the peregrine may be entangled at one level, but are emphatically not the same. "I like being able to glance up from my own everyday business," she says, "to see the osprey or the peregrine go about hers" (46). This frisson of recognition is then intensified by her knowledge that these sightings are relatively rare occurrences. "What it is about the peregrines is their rarity. I'm sure they're gone now, but for a while I enjoyed the pleasure of a warm secret: I could watch the uncommon and handsome bird from my own window, and know it was there" (4647). That these "warm secrets" are shared with us is part of the appeal of Jamie's writing, which ultimately turns it back upon the "falconer's worship of mastery, [and] the wish to identify with terror, with the predator over its prey" (46).

A rather different examination of the masculinist myths surrounding falconry can be found in the work of T. H. White, still best known today for his suitably garish Arthurian romantic novels, but whose scarcely less melodramatic nature memoir The Goshawk, written in the immediate World War II period, has come to acquire a minor cult status of its own. The Goshawk, the story of its solitary author's increasingly manic attempts to train the titular bird, is probably most interesting today for the glaring contradictions that accompany a hysterical anti-modern crusade written almost entirely from a modern sensibility, and explosively bringing together romantic and modern imaginaries, the one fuelled by ancestral longing, the other by present misery and despair. The hawk itself is an ancestral figure, the living embodiment of its excitable author's "excursion [out] into the fields and back into the past" (16). This untutored excursion, and the equally amateurish training it involves, are likened to a mock-trial in 
which White doubles as unwilling executioner and tormented victim, exchanging these roles as often as the "trained" hawk turns from flesh-shredding apex predator to human symbolic prey.

As the tale proceeds, this trial turns into a kind of medieval mortification rite - a submission of the self to punishment for the sake of others - which, in a not entirely dissimilar manner to Baker's The Peregrine, shoots off sparks of modern warfare and civilizational collapse (52). Also like Baker, White clearly envies the hawk - for its hugely powerful presence, for its vastly superior powers of vision - but for these selfsame reasons he is terrified of it, acutely aware that "hawk vision" allows for the imagination of killing, but also of being killed (67-68). As these fears increase, the hawk becomes a powerful vehicle for White's frustration and pent-up rage: against "civilized" society, against the warmongering modern world, but most of all against himself. "What right had a cowardly recluse who fled from his fellow men [...] to write about these almost fabulous creatures?" (75). Here as elsewhere in the text, White's feeble attempts at hawk training turn into a post-Romantic exercise in self-estrangement, for it is not the hawk that is other, but White (who likens himself at one point to Frankenstein) who is other to himself.

There is not much to be learned about hawks in the text, and White freely admits that he doesn't know much about them either; rather, the text enacts a semi-parodic mating of raging souls in which the hawk, "haunted by moods and mania" (99), becomes an objective correlative for White himself. Indeed, The Goshawk is stalked by madness from beginning to end, a condition that goes far beyond the foolishness of its own enterprise, gesturing instead towards a collapsed world order that can neither be redeemed nor rectified, and over which the image of the hawk magisterially presides as a latter-day Attila-figure, a legendary tyrant who "immolated victims, sacked cities, [and] put virgins and children to the sword" (172).

White's livid martial fantasies are a far cry from the more intimate scenes of transspecies encounter we find in Helen Macdonald's 2014 memoir $H$ is for Hawk; nonetheless, The Goshawk is obviously a formative influence on Macdonald, whose text deliberately situates itself in White's shadow and consciously engages with the estranged modern condition that it both dolefully inhabits and energetically attacks. Reversing the temporal order of their respective texts, Macdonald refers to White at one point as a projected Merlin figure, "an imagined future self" (247). It's clear though that White, the story of whose mental and physical turmoil is interwoven with Macdonald's memoir, is less the legendary magician of his own romantic imagination than a

Humanimalia: a journal of human/animal interface studies

Volume 12, Number 1 (Fall 2020) 
deliberately unbalanced modern figure, the unstable origin of a calculated negotiation between an unwanted (war-torn) future and an equally violent past.

In this context, $H$ for Hawk is much more than the female-centred recovery narrative it has sometimes been taken to be; rather, it is a failed attempt at human-animal reconciliation mapped onto an untimely contemplation of the fragmented modern self. This isn't to say that the text doesn't operate at one level as a chronicle of bereavement, but it is melancholic rather than mournful, and the moments of peace and communion it finds are essentially Woolfian "moments of being," temporary discoveries that reconfirm an overarching sense of loss $(106,117,181) .{ }^{4}$ As in The Goshawk, the struggle for self-control remains unresolved, and the text fights in any case against its own "strategies of containment" (Jameson). ${ }^{5}$ It wants the wild, which is symbolized by the hawk, but knows full well that it can't have it; and continuing in the search to have what it can't have, it deliberately places itself in harm's way, fearing that the opposite of wild isn't tame, but rather that deadening aspiration of modern bourgeois civilization, safe $(143,189)$.

In this sense, $H$ is for Hawk is what the late German sociologist Ulrich Beck might have called a "risk narrative," in which the authenticity of modern lived experience is gauged by the capacity to exhibit one's own vulnerability to external forces; as Beck apodictically puts it, "I risk, therefore I am" (5). What is primarily at risk though, as in White's prior text, is not physical but mental wellbeing. And, as Macdonald comes increasingly to recognize, the wildness for which the hawk has been made to stand is less a panacea than an illusion; it is also a fundamental misunderstanding of how the hawk lives - not that this understanding can ever be fully arrived at any more than the category of the wild itself is available to human cognition (275).

What this leaves us with, I would suggest, is a necro- rather than biopolitical approach to the human-animal relationship that is played out through initiation, a secret if publicly shared rite, bound up with death and sacrifice, in which to encounter the wild animal is also to conduct a "conversation with death" (Macdonald; see also Mbembe) ${ }^{6}$ All four texts I have just been examining here are initiations of a kind, although it is arguably only in the earlier texts, White's and Baker's, that the animistic dimensions of their human-animal encounters are fully acknowledged and played out. These initiations, though deeply personal, elevate the texts to the status of myth. They also convey an element of obsession or addiction that is the flip side of a modern "dissociated sensibility" (Eliot) - one that, in resituating the self as other, causes us to 
seek with seemingly increasing desperation reanimating connections with others' lives. ${ }^{7}$ Modern British animal writing registers precisely this attempt, not so much to recapture what has been lost but to find an animating drive, discovered in our encounters with (other) animals, that might give temporary meaning and energizing significance to our everyday lives.

This drive is as likely to be oriented towards death as towards life: hence the double coding of a great deal of this writing, which seeks affective solidarity with animals that kill for survival rather than sport, and whose death-instincts operate as risk-filled registers for revitalized human lives. This uncompromising view comes at a price, though I think it would be going too far to accuse such writing of nihilism; rather, in cases such as Baker's at least, it conveys an immense frustration with human foolishness and arrogance that is reflected at a visceral level in the violent human-animal (and animal-animal) encounters that are retrospectively rehearsed in the text. In the next section of this essay, I want to reflect further on the violence encoded in recent and contemporary British animal narratives, associating it this time with otters, not the most obviously violent of creatures, but ones that feature in some of British literature's most conspicuously violent texts.

Otter Others. The obvious place to start is with Henry Williamson's Tarka the Otter, first published in 1927 but still as fresh and unsettling as ever, its instilled violence further intensified by recent biographical accounts of its traumatized author's life (Yeates). Read today, Tarka comes across as an X-rated beast fable in which otters, often as violent as the human hunters who see them as pests, feature as hyperkinetic creatures, always on the move, constantly alert, driven by hunger but also by what appears - to human eyes at least - like a permanent condition of jittery nerves. Tarka is a novel, though hardly one made up. The product of thousands of hours of painstaking field research by Williamson, it is as much an unsparing portrait of Dartmoor, a oncebeautiful landscape increasingly scarred by human use, as a searing indictment of human injustices towards animals (and, though this is not a central feature of the text, toward each other and themselves).

Tarka is also very much a crisis text: describing the fateful collision of ancient and modern worlds, it both simulates an ancientness it cannot grasp and inhabits a modernity it cannot tolerate, with its headlining otters, unable to find a place in either, the very embodiment of what Zygmunt Bauman, in an updated urban context, has described as "modernity's outcasts," condemned to eke out "wasted lives" (Bauman). If this makes the text seem sentimental, it is anything but, and violence is its standard

Humanimalia: a journal of human/animal interface studies

Volume 12, Number 1 (Fall 2020) 
commodity. One typical sequence witnesses the charmingly named Izzywig the hedgehog ("vuz-peg" in local dialect) unceremoniously turned over, protective spines demobilized, and devoured from the inside (44). To be sure, parts of the text, registered from the otter perspective, read like a celebratory local ethnography of otter culture, replete with Devonian inflections and Kiplingesque gestures toward zoological primitivism (which, as in The Jungle Book, is primarily intended to confer dignity on the animal world). But the violence is unrelenting, and in Tarka's post-primitivist world it really does amount to eating or being eaten; there is little time to ponder alternative courses of action, and indeed little time to do anything at all, such is the constant race to find the psychological wherewithal as well as the physical opportunity to survive.

Published more than thirty years after Tarka, Gavin Maxwell's Ring of Bright Water is similarly written out of an intensely disappointed (in Williamson's case, quasimisanthropic) apprehension of the violence inherent in modern "civilized" life. In Maxwell's case, this leads him to Camusfeàrna, a lonely made-up place on the northwest Scotland coast whose real location, which would later ironically become a major tourist draw, is withheld from the reader lest its "identification in print [should] bring nearer its enemies of industry and urban life" (5). This is the stage, Maxwell tells us in the Foreword, for an escape from "the prison of adult life" in which the imaginative possibility is explored of looking at "some portion of the earth as it was before [man] tampered with it," and in so doing of restoring the broken connection that modernity has created between mankind and "the other living creatures of the world."

Some readers (and Ring of Bright Water remains one of the best-selling animal books of all time) may take Maxwell at his word, but many, I suspect, are wary of him; indeed, it is the stereotypically idyllic quality of Maxwell's scene-setting which - and not just for contemporary readers who know the story already - creates an initial impression of unease which quickly gathers momentum in the text. The two otters Maxwell brings into his household (first Mijbil, then Edal) are the temporary stars of the show, but just as they are never entirely trainable, the trust that builds up between human and animal exists under a permanent shadow that belies the brightness and light-heartedness that are surface features of the text. To put it bluntly, the Camusfeàrna project is doomed from the start, not just because there is no more chance of understanding the otters than of maintaining the enchanted status of their coastal sanctuary, but also for the obvious reason that otters, however charming they look and entertainingly they behave, are not, nor were ever meant to be, household pets. 
Seen in this context, the greatest violence in the text is not the bludgeoning of Mijbil, heart-rending though it is, but the decision to buy and keep him in the first place; and in this and other respects, Ring of Bright Water joins other human-animal encounter narratives of its period, notably Gerald Durrell's My Family and Other Animals, as a kind of anti-model for modern animal conservation - not that it was ever intended to be a conservationist text. Whatever the case, Ring of Bright Water, read today, lacks the altruistic charm that it seems to have had for contemporaneous readers; instead, it is more likely to come across as a damaging portrayal of the possessive individualism of Maxwell himself. There is a kind of childish petulance at work in the text, such as when Maxwell, proud of having achieved the childhood goal of owning an animal that bears his own name (a "Maxwell's otter"), curses any "odious taxonomist of the future" who might dare take that name away from him (103). In his defence, there is gentle selfmockery, too, such as in one later episode when, out on one of his morning walks with Edal, he whistles to bring her back only to find himself confronted instead by a wild otter, "staring at me with interest and surprise" (153). Seeing that he is no threat, the otter sticks around for another look, then "resume[s] his leisurely progress southward along the edge of the rocks." Edal, meanwhile, is left to forage for crabs, small fish, and shrimps; when she gets back "home," she will probably be rewarded with some eels, served up alive to her in her makeshift training tank (154).

The passage offers a more affecting account of the consequences of captivity than any of the partly staged calamities, which accumulate quickly later in the trilogy, that befall human and animal victims alike. It is important not to be sanctimonious. Ring of Bright Water is a product of its time, and it is probably more revealing of human frailty than of animal vulnerability, though both of these are tangled up with one another as well as with a number of material practices and agencies (local fishing and agriculture, the national tourism industry, the global wildlife trade) that turn it from the affecting story of one man's encounter with wild animals into a modern "multi-participatory" text (Haraway). ${ }^{8}$

It still seems worth wondering, though, what kind of knowledge is transmitted by books such as Maxwell's (and, in a rather different context, Williamson's) which, for several generations of child and adult readers, have helped shape an understanding of British otters' still tenuous place in the modern world. As Miriam Darlington, to whose Otter Country (2012) I now turn, "much of what we think about otters [today] is mediated by television and by books like Tarka and [...] Ring of Bright Water" (18). In the 1960s, she continues, "keeping pet otters made Maxwell famous. His lyrical account of life with otters in the wild emptiness of the Highlands was highly seductive, but how

Humanimalia: a journal of human/animal interface studies

Volume 12, Number 1 (Fall 2020) 
much did it actually tell us about otters? The enraptured descriptions reveal nothing of the conflicts that emptied the land of its people and little of the reality of keeping wild animals in captivity."

This is true to a large extent of Ring of Bright Water if not of Tarka, which as argued earlier is in line with a great deal of twentieth-century British animal writing precisely for what it reveals about the violent modern world in which humans and other animals interact. Darlington's search for the animal behind the tale is thus possibly based on false premises, though this is partly the result of her chosen medium, the footsteps narrative, which is by definition belated with respect to the real and imaginative journeys it seeks to re-enact. Footsteps narratives are caught in a cleft stick between critique and commemoration, with involuntary reverence being one potential end result. They are also good examples of "postmemory" texts, that is, texts that rely on representation to make up for their lack of direct experience (Hirsch). This doesn't mean that works such as Otter Country are condemned to one form or another of experiential inauthenticity, but rather that they depend, to an even greater degree than the works they follow, on an understanding of what the visual theorist Steve Baker calls the "symbolic availability" of animals as instruments for human needs and desires (5). As Baker suggests, "Attitudes to living animals [today] are in large part the result of the symbolic uses to which the concept of the animal is put in popular culture. This is not to set the representational or the popular-symbolic 'over' the real. It is simply to say that any understanding of the animal is inseparable from knowledge and its cultural representation" (Baker 25; see also Armstrong and McHugh).

Otter Country, seen in this context, is not one but a variety of cross-hatched quest narratives, in which different temporalities coincide, real and imagined animals coparticipate, and the larger symbolic figures of the otter and the animal itself are productively engaged with as ways of both decentering and paradoxically re-centering the human subjects of these narratives, creating a "multispecies" mixture of biography and autobiography at the core of which stands the questing author herself (Kirksey). ${ }^{9}$ This nesting of narratives probably makes the text sound more experimental than it is, and much of the book is a fairly standard account of Darlington's energetic search for otters across some of the more remote places of Britain, seen alongside and in conversation with her analysis of Maxwell and Williamson's writing, which is in turn enmeshed with their everyday working lives. 
Human and animal subjects prove equally elusive, however, and Darlington stresses the difficulties involved in a multi-scalar tracking process that involves the imaginative crossing of time as well as the material crossing of space. Failure would be too strong a word to describe the result, but like other contemporary writers Darlington is well aware that there is only fleeting access to the creature in the flesh, and that most of the time the human quest for the animal turns full circle. This dilemma is writ large in what is probably the greatest temptation of all in animal writing-performatively to "become" the animal that one can only imaginatively represent. A late scene in Otter Country demonstrates this nicely. Near her home in Devon, Darlington discovers a set of otter tracks, and briefly imagines what it must be like to be an otter. Crouching in the mud, she tries to recreate the view an otter might have as it comes out of the marsh.

At the edges [of the river], water and mud lose themselves together. Higher up, oak trees and rock are moored to the bank, and there are dry places between trunks to curl up. I place myself in the crook of a rock and a woody root, and my nostrils fur with earth-odours. If I were a hungry otter I would follow the rim of the crumbling wall and bank, blending myself with the contours, and later drop down a level to the rocks to search for crayfish and eels as they emerge on the rising tide. (333)

Sensing that she is close to the otters, she goes in after them, swimming otter-style with her nose at water level (335). The otters themselves never appear, and the scant reward for her efforts is to catch two human swimmers, youths skinny-dipping like her in the murky river, embarrassingly unawares. This unsolicited return to the human world makes perfect sense as an ending to the narrative; it also reinforces the delusion of "becoming an animal" that the text intermittently presents. One last text in my essay not only explores this delusion, but also actively performs it. This is Charles Foster's astonishing 2016 thought-experiment, Being a Beast.

Being a Beast is nothing if not a risky book. The Author's Note at the beginning says it is motivated by the dual desire "to know what it is like to be a wild thing" (xi) and to counteract the mock-triumphal tendencies of nature writing, which Foster sees as "generally [being] about humans striding colonially around, describing what they see from six feet above the ground, or about humans pretending that animals wear clothes." He posits an alternative: to "see the world from the height of naked Welsh badgers, London foxes, Exmoor otters, Oxford swifts and Scottish and West Country red deer," but in so doing to chart the olfactory and auditory rather than the purely visual dimensions of animal life. The problem with this approach, as Foster well knows,

Humanimalia: a journal of human/animal interface studies

Volume 12, Number 1 (Fall 2020) 
is that it is impossible. Being a Beast is the confessional record of that impossibility, played out across a series of madcap scenes (Foster "as" badger, "as" fox, "as" otter, etc.) that have been read by some reviewers as funny but are best seen as an awkward cross between the plaintively melancholic and the patently absurd.

The absurdity of the exercise doesn't mean that it is meaningless. Foster is genuinely interested in how animals smell, touch, and feel, and how they negotiate the world from their own species-specific vantage point. He is also genuinely committed to trying to live the lives they lead, whether it is living in a hole and eating slugs (like country badgers) or wandering the streets at night and foraging in rubbish bins (like city foxes). Moreover, as a trained vet he is knowledgeable about animal cognition and physiology, and in this sense Being a Beast is empiricism with a difference, backed by detailed scientific observation if still primarily devoted to experimenting first-hand with the (animal) senses so as to develop a heightened (human) sensory appreciation of the phenomenal life-world.

The imagination also obviously comes into play here, and indeed Foster describes his book as a "sort of literary shamanism" (xi). It is shamanism of a very different order, however, than what we see in the work of Baker and Williamson. Shamanism implies the visionary capacity to transform and/or be transformed - to cross the boundaries between different worlds - but Foster knows he is trapped inside his human body. He can no more become the animals whose actions and behavior he attempts to copy than he can unlock the secret behind "becoming-animal," Deleuze's dizzying postontological vision of the incessant "becomings that compose different [human/animal] bodies," which effectively turns all creatures, including ourselves, into affective animals, part of a larger network of ecological relations that continually constitutes and reconstitutes itself (Buchanan 159, 161). ${ }^{10}$

Not that Foster doesn't try, and there are moments in the text, such as when, after spending a summer living water-bound "as" an otter, he manages to convince himself that he is a shaman after all (93). But the approaching winter brings him back to earth, and his creeping sense of futility returns:

This tells me something worth knowing. A depressed shaman, hunter or naturalist can't work at all. A grey soul, apparently, can't penetrate that thin veil between the species. I don't understand the metaphysics. But it seems that you have to be sufficiently ' $\mathrm{I}$ ' to be another, and depression 
erodes the ' $\mathrm{I}$ ' below the critical point. Perhaps, for a human, being an animal is just an extreme mode of empathy - no different in kind from what you need to be to be a decent lover or father or colleague. When you're depressed you might simply be nursing that injured ' $\mathrm{I}$ ' too obsessively to have the energy or attention necessary for empathy. Our nursing strategies are radically misconceived. They all tend to be based on the disastrous misconception that if you give away your Self there will be less of you. In fact of course (as we know when the sun shines), the very opposite is true. (93)

Confessional moments like this give the book an elegiac feel, as if it is already apologizing in advance for the diminished empathy and stunted sensory perception that its melancholic author sees as being the inevitable by-products of contemporary half-living in a "post-natural" Anthropocene world (Purdy). His main counter-strategy seems to be a visceral form of self-abasement, but this - by his own admission - is only temporary, and the text is often marked by a glaring (if also guilty) lack of empathy, seen in his "Otter" chapter in his high-handed treatment of both Williamson and Maxwell, and in his forked-tongue revelation of the one advantage he has "over those true masters of otter writing: I don't like otters very much" (71).

A few taut pages on otter physiology follow, in which otters are uncompromisingly described as pound-for-pound killing machines, "jangling, snarling, roaming, twitching bundles of ADHD" (73). By the end of the chapter Foster has calmed down, his point already having been made, but his mood will swing again in the next chapter, and the next. In this respect, Being a Beast is less a thought- than a mood-experiment, in which different animal species are mapped onto its human author's continuously fluctuating neurological chart. Odd though it is, Foster's writing is in fact a logical progression of the self-lacerating kinds of modern animal writing I have been looking at in this essay, which often tend to admit the impossibility of empathetic relations with (other) animals - even if this is precisely what they seek. To some extent, this is an effect of the souldestroying modern conditions with which this writing grapples rather than a consequence of its repeated failure to cross the species barrier; more specifically, it is connected to the modern dissociated self.

The ecological orientation of much of this writing is not an antidote to these conditions, but rather a symptom of them. My contention is that what drives modern British animal writing is, above all, a general apprehension of loss that carries over into an uncanny feeling of lateness - the idea that the time is either out of joint or, still worse, that time

Humanimalia: a journal of human/animal interface studies

Volume 12, Number 1 (Fall 2020) 
itself may be running out. (In some apocalyptic strands, time may well be felt to have run out already.) If this is an ecological idea, easily translated into the contemporary mantras of the new materialism and the Anthropocene, it is also at heart a deeply human one. ${ }^{11}$ What this means is that modern British animal writers are condemned to repeat what Foster calls the "two sins [that] have beset traditional nature writing: anthropocentrism and anthropomorphism" (xii). Whether animal writing is in fact "nature writing" is a moot point, and I have been arguing in this essay that the two have different sets of priorities and concerns. But it is certainly the case that animal writing, and the particular examples of the genre I have been looking at here, function as an affective barometer for human fears and anxieties that have both distinctly historical and broader existential dimensions - fears and anxieties about human selfworth and identity that are redoubled by the animals that humans recognize in themselves.

\section{Notes}

1. The Anthropocene - the so-called Human Age, marked by the simultaneous ubiquity and intensity of human influence on the planet - has unwittingly reinforced the idea of human centrality even as its ecological underpinnings maintain just the opposite: that human beings, as much shaped by as shaping the different worlds they fashion, are co-dependent inhabitants of a precariously shared earth. One of the best of the many books that have effectively created an academic cottage industry around the Anthropocene is After Nature, by the American environmental lawyer Jedediah Purdy. Purdy argues that the Anthropocene can be seen as the basis for a "new politics of nature, a politics more encompassing and imaginative than what we have come to know as environmentalism" (17). However, he also points out that the Anthropocene is characterized by an atmosphere - a condition - of potentially debilitating uncertainty: over what global environmental action to take; over what local social practices and policies to implement; and, not least, over how to rethink the ways in which both human and nonhuman worlds are imagined within the overall framework of what he ambitiously calls an "aesthetics of [global] change" (245). Such a transformative aesthetics, he suggests, urgently needs to find a place within it for the uncanny: for the "unsettling perception that we do not know, perhaps cannot know, the ethical status, meaning, or experience of another living being that stands in front of us" (230). In the human-animal domain, this means "admitting that we don't know what an animal's life means, to it or us, and that the answer we can give can only be some blend of discernment and projection" (244). I have dwelt on Purdy here because his work, UScentered though it is, goes further than most in staking out the territory for 
contemporary UK-based animal writing, which brings together just the combination of characteristics - uncanny aesthetics, epistemological uncertainty, ecological interconnectedness - he explores. Following Purdy, I see modern British animal writing as being caught in an "Anthropocene condition" of failure that is marked by the unbridgeable distance between experience and representation, and by the gulf of incomprehension between different life-worlds.

2. Thanks to Kate Marshall for bring the term "pseudo-extinction" to my attention. Understandings of pseudo-extinction vary, with the most widely accepted, biological definition referring to the extinction of a parent species while an affiliated sub-species is still alive (de Vos). My own understanding of pseudo-extinction, derived from Marshall's, differs from this. For further reflections on pseudo-extinction, see Marshall; also Armstrong.

3. Like Donna Haraway, whose ideas are behind much of what I say in this and other work, I prefer the term "transspecies" to its more commonly used counterpart, "interspecies," on the grounds that the prefix "inter" implies fixed boundaries around species that most human-animal theorists vigorously contest. (See, for example, Wolfe; also Haraway.)

4. "Moments of being," which now gives its name to a posthumous (1972) collection of autobiographical essays by Woolf, are those moments in which individuals experience an awakening sense of the reality behind appearances, as opposed to the deadening state of "non-being" that affects and afflicts us in most of our daily lives.

5. "Strategies of containment," as Fredric Jameson explains, are ways of dealing with contradiction by constructing substitute truths that limit the damage history does to us (see, for example, Jameson). I am using the term loosely here to describe White's attempts to control contradiction by accommodating it - strategies that are inevitably, and indeed conspicuously, unsuccessful in his work.

6. "Necropolitics" is the Cameroonian philosopher Achille Mbembe's term for what he calls "the subjugation of life to the power of death" (39) - a subjugation he sees as exceeding the regulatory bounds of biopolitics. I am using the term here to convey the sense in which animal writing is bound up in practices of death and sacrifice that often have a quasi-ritual aspect (for an in-depth treatment of this, see Wolfe and Shukin). In Helen Macdonald's more prosaic but no less terrifying terms, human encounters with animals are "conversations with death" and animal writing, operating as one of the

Humanimalia: a journal of human/animal interface studies

Volume 12, Number 1 (Fall 2020) 
primary vehicles for such encounters, often examines the "necropolitical" relations behind them ( $H$ is for Hawk 29). New materialist thought - of which more later - has generated a fresh interest in animism as part of the wider transformative process by which bodily exchanges (both human and nonhuman) enact material and spiritual transfers from one state to another, including the ritual passage between life and death. I have no scope to examine this further here although it would be fruitful to do so, and animal writing more broadly stands to benefit from the necro/biopolitical approaches adopted in Wolfe and Shukin's (and, to a lesser extent, Alaimo's and Haraway's) work.

7. The term "dissociated sensibility," now used in contexts that far outstrip its original usage, derives from T.S. Eliot's 1921 essay "The Metaphysical Poets," where he uses it to describe a newfound sense of the separation of thought and felt experience in some seventeenth-century literary works. The "splitting" of the self that ensues has been seen as a hallmark of the modern (Western) sensibility, and whether this is attributable or not to Eliot, it certainly applies to modern British animal writing, in which the dissociated sensibility, further magnified by the mutual gulf of incomprehension that separates human beings from (other) animals, is writ large.

8. The idea of "multi-participation" is probably at its most visible in new media studies, where it refers to the apparently ever-increasing capacity of media users to work across several different platforms at once. For Donna Haraway among others, this idea is extended to include the multiple, transverse relations that exist between often markedly different social actors, both human and nonhuman, and the representation of those relations across an equally wide range of cultural texts.

9. The idea that we live in a "multispecies" world has rapidly become axiomatic, spreading to fields well beyond animal and human-animal studies, with several recent interventions in anthropology, biology, geography, literary criticism, and philosophy, disciplines that are already incorporated to some extent into the methodological protocols of animal studies itself. The term "multispecies" (usually unhyphenated) refers to a shared method as much as a shared world, in which theorists and practitioners attempt systematically to break down what Val Plumwood calls the "hyperseparations" that have historically regulated human-animal relations, reinforcing the boundary between them and consolidating ideas and illusions of human mastery over the natural world. Multispecies assemblages of different kinds have also been integral to new materialist thought (see also Note 11 below), at least some of which is closely affiliated with posthumanism, itself a collage of related methods that is 
explicitly designed, not just to challenge the idea of human centrality, but to question the idea of the human itself. One might expect animal writing to be inherently multispecies, but this is in fact far from the case, as the wider history of the "symbolic availability" (S. Baker) of animals for changing human needs and purposes attests. Animal writing may not only be about humans, but it continues to be mostly about humans, just as nature writing, an always-tricky category that is by no means synonymous with animal writing, continues to negotiate the tension between its egocentric inclinations and its ecocentric claims.

10. For the original discussion of "becoming-animal," see Deleuze and Guattari.

11. The new materialism, perhaps better seen as loose constellation of related approaches than as a unified philosophy or movement, has rapidly evolved into a new orthodoxy in ecocriticism, though - like ecocriticism itself - it ranges across a number of different disciplines that may have little or nothing to do with the reading of literary texts. New materialist approaches tend to stress the agential capacity of matter, the coimplication of nature and culture, and the entanglement of all (human and nonhuman) life forms. For a useful overview of these approaches, see Coole and Frost; for their application to human-animal studies, see the work of the Sydney-based Human Animal Research Network (e.g. Animals in the Anthropocene); also Wright.

\section{Works Cited}

Alaimo, Stacy. Bodily Natures: Science, Environment, and the Material Self. Indiana UP, 2010.

Allen, Daniel. Otter. Reaktion Books, 2010.

Armstrong, Philip. What Animals Mean in the Fiction of Modernity. Routledge, 2008.

Baker, J.H. The Peregrine. 1967. Collins, 2015.

Baker, Steve. Picturing the Beast: Animals, Identity, Representation. U of Illinois P, 2001.

Baker, T.C. Writing Animals. Palgrave, 2019.

Bauman, Zygmunt. Wasted Lives: Modernity and its Outcasts. Polity Press, 2002.

Humanimalia: a journal of human/animal interface studies

Volume 12, Number 1 (Fall 2020) 
Beck, Ulrich. World at Risk. Routledge, 2009.

Berger, John. About Looking. 1980. Bloomsbury, 2009.

Buchanan, Brett. Onto-Ethologies: The Animal Environments of Uexküll, Heidegger, MerleauPonty, and Deleuze. SUNY, 2008.

Coole, Diana and Samantha Frost, eds. New Materialisms: Ontology, Agency, and Politics. Duke UP, 2010.

Darlington, Miriam. Otter Country: In Search of the Wild Otter. Granta Books, 2012.

Deleuze, Gilles and Félix Guattari. A Thousand Plateaus: Capitalism and Schizophrenia. 1987. Bloomsbury, 2013.

De Vos, Rick. "Extinction Stories: Performing Absence(s)." Knowing Animals. L. Simmons and P. Armstrong, eds. Brill, 2007. 183-195.

Durrell, Gerald. My Family and Other Animals. Hart-Davis Publishers, 1956.

Eliot, T.S. "The Metaphysical Poets." Metaphysical Lyrics \& Poems of the Seventeenth Century. Herbert J.C. Grierson, ed. Clarendon Press, 1921.

Farrier, David. “The Peregrine and its Readers.” ISLE 22.4 (2015): 742-758.

Foster, Charles. Being a Beast. Profile Books, 2016.

Halley, Jean and Patricia Ticineto Clough, eds. The Affective Turn: Theorizing the Social. Duke UP, 2007.

Haraway, Donna. When Species Meet. U Minnesota P, 2008.

Heise, Ursula. Imagining Extinction: The Cultural Meanings of Endangered Species. Columbia UP, 2016.

Herman, David. Creaturely Fictions: Human-Animal Relations in Twentieth and TwentyFirst Century Literature. Palgrave, 2016. 
Hirsch, Marianne. The Generation of Postmemory: Writing and Visual Culture After the Holocaust. Columbia UP, 2013.

Huggan, Graham. "Back to the Future: 'The New Nature Writing,' Ecological Boredom, and the Recall of the Wild." Prose Studies 38.2 (2016): 152-171.

Human Animal Research Network. Animals in the Anthropocene: Critical Perspectives on Non-human Futures. Sydney UP, 2015.

Jameson, Fredric. The Political Unconscious: Narrative as a Socially Symbolic Act. Routledge, 2002.

Jamie, Kathleen. Findings. Sort of Books, 2005.

Kalof, Linda and Georgina M. Montgomery, eds. Making Animal Meaning (The Animal Turn). Michigan State UP, 2012.

Kirksey, Eben, ed. The Multispecies Salon. Duke UP, 2014.

Lippitt, Akira. Electric Animal: Toward a Rhetoric of Wildlife. U Minnesota P, 2008.

Macdonald, Helen. Falcon. Reaktion Books, 2016. . H is for Hawk. Vintage, 2014.

Macfarlane, Robert. "Violent spring: The nature book that predicted the future." The Guardian, 15 April 2007. Online.

Marshall, Kate. "What Are the Novels of the Anthropocene? American Fictions in Geological Time." American Literary History 27.3 (2015): 523-538.

Maxwell, Gavin. Ring of Bright Water. 1960. Penguin, 2001.

Mbembe, Achille. “Necropolitics.” Public Culture 15.1 (2003): 11-40.

McHugh, Susan. Animal Stories: Narrating across Species Lines. U Minnesota P, 2011.

Humanimalia: a journal of human/animal interface studies

Volume 12, Number 1 (Fall 2020) 
McHugh, Susan, Robert McKay, and John Miller, eds. The Palgrave Handbook of Animals and Literature. Palgrave, 2020.

Nyman, Jopi, and Nora Schuurman, eds. Affect, Space and Animals. Routledge, 2017.

Plumwood, Val. Environmental Culture: The Ecological Crisis of Reason. Routledge, 2001.

Purdy, Jedediah. After Nature: A Politics for the Anthropocene. Harvard UP, 2015.

Ritvo, Harriet. The Animal Estate: The English and Other Creatures in Victorian England. Harvard UP, 1989.

Shukin, Nicole. Animal Capital: Rendering Life for Biopolitical Times. U Minnesota P, 2009.

Silverman, Kaja. The Threshold of the Visible World. Routledge, 1996.

Van Dooren, Thom. Flight Ways: Life and Loss at the Edge of Extinction. Columbia UP, 2014.

Weil, Kari. “A Report on the Animal Turn.” differences 21.2 (2010): 1-23.

Williamson, Henry. Tarka the Otter. G.P. Putnam's Sons, 1927.

White, T.H. The Goshawk. 1951. Weidenfeld \& Nicolson, 1964.

Woodward, Wendy. The Animal Gaze: Animal Subjectivities in Southern African Narratives. Wits UP, 2008.

Wolfe, Cary. Animal Rites: American Culture, the Discourse of Species, and Posthumanist Theory. U Chicago P, 2013.

Woolf, Virginia. Moments of Being: Autobiographical Writings. 1972. Pimlico, 2002.

Wright, Kate. Transdisciplinary Journeys in the Anthropocene. Routledge, 2018.

Yeates, Guy. Henry Williamson: The Author as Fascist. Independently published, 2017. 